\title{
A stimulatory TSH receptor antibody enhances adipogenesis via phosphoinositide 3-kinase activation in orbital preadipocytes from patients with Graves' ophthalmopathy
}

\author{
Seema Kumar ${ }^{1}$, Sarah Nadeem ${ }^{2}$, Marius N Stan ${ }^{2}$, Michael Coenen ${ }^{2}$ \\ and Rebecca S Bahn ${ }^{2}$ \\ ${ }^{1}$ Division of Pediatric Endocrinology and Metabolism and ${ }^{2}$ Division of Endocrinology, Diabetes and Metabolism, Mayo Clinic, 200 First Street SW, \\ Rochester, Minnesota 55905, USA \\ (Correspondence should be addressed to R S Bahn; Email: bahn.rebecca@mayo.edu)
}

\begin{abstract}
Graves' ophthalmopathy (GO) is characterized by expanded volume of the orbital tissues associated with elevated serum levels of TSH receptor (TSHR) autoantibodies. Because previous studies have demonstrated evidence of adipogenesis within the GO orbit, we sought to determine whether M22, a human monoclonal antibody directed against TSHR, enhances adipogenesis in orbital fibroblasts from patients with $\mathrm{GO}$ and, if so, to identify signaling mechanisms involved. GO orbital fibroblast cultures $(n=10)$ were treated for 10 days with bovine TSH ( 1 or $10 \cdot 0 \mathrm{U} / \mathrm{l})$ or M22 (1 or $10 \mathrm{ng} / \mathrm{ml})$ in serum-free adipocyte differentiation medium. Some cultures also received a phosphoinositide 3-kinase (PI3K) inhibitor or an inhibitor of cAMP production. In other experiments, confluent cultures $(n=8)$ were treated for between 1 and 30 min with TSH $(0 \cdot 1-10 \cdot 0 \mathrm{U} / \mathrm{l})$ or M22 $(0 \cdot 1-100 \mathrm{ng} / \mathrm{ml})$ with measurement of cAMP production or levels of phosphorylated AKT (pAKT). We found levels of adiponectin, leptin, and TSHR mRNA to be increased in GO cultures treated for 10 days with either M22 (2.6 mean fold $\pm 0 \cdot 7 ; P=0 \cdot 03$ ) or TSH (13.2 $\pm 5 \cdot 8$-fold, $P=0 \cdot 048)$. In other studies, M22 and TSH stimulated cAMP production and pAKT levels in GO cells. Inhibition of PI3K activity during 10 days in culture decreased the levels of M22-stimulated mRNA encoding adiponectin ( $67 \pm 12 \% ; P=0.021)$, as well as adiponectin and CCAAT/enhancer-binding protein $\alpha$ protein levels. In conclusion, M22 is a pro-adipogenic factor in GO orbital preadipocytes. This antibody appears to act via the PI3K signaling cascade, suggesting that inhibition of $\mathrm{PI} 3 \mathrm{~K}$ signaling may represent a potential novel therapeutic approach in GO.
\end{abstract}

Journal of Molecular Endocrinology (2011) 46, 155-163

\section{Introduction}

Graves' ophthalmopathy (GO) is an inflammatory autoimmune disorder involving the fatty connective tissue and the extraocular muscles within the bony orbit (Bahn 2010). Many of the signs and symptoms of GO, including proptosis and ocular congestion, result from expansion of these tissues. While striking enlargement of the extraocular muscles is evident in some patients, and in others expanded volume of the orbital adipose tissue predominates, the majority of patients show expansion of both tissues (Forbes et al. 1986). While the enlargement of the extraocular muscles is caused by an accumulation of hydrophilic hyaluronan between the muscle fibers (Smith et al. 1989), the expanded orbital adipose tissue volume is thought to be due to both enhanced adipogenesis and the accumulation of hyaluronan within these tissues (Kumar et al. 2004). The formation of new fat cells within the orbit suggests that resident preadipocytes are stimulated by some
GO-specific factor to undergo adipocyte differentiation. Preadipocytes are a subpopulation (15-20\%) of fibroblasts cultured from the orbital adipose/connective tissues capable of differentiating into mature adipocytes (Kumar et al. 2004).

GO is closely associated with Graves' hyperthyroidism, a condition in which overproduction of thyroid hormones by thyroid follicular cells is stimulated by TSH receptor (TSHR) autoantibodies (TRAb). TSHR mRNA and protein are detectable in both normal and GO orbital adipose tissues (Feliciello et al. 1993, Heufelder et al. 1993, Mengistu et al. 1994, Bahn et al. 1998), with the highest levels found in orbits of GO patients having active disease (Wakelkamp et al. 2003). Furthermore, levels of circulating TRAb correlate with the clinical activity of the disease (Gerding et al. 2000) and predict disease severity (Eckstein et al. 2006). Due to the close clinical relationships between Graves' hyperthyroidism and GO, and the presence of TSHR in orbital tissues, it has been hypothesized that 
circulating TRAb in Graves' disease target TSHR within the orbit and stimulate some of the histopathological changes characteristic of the disease.

Most of the activities of the TSHR in thyrocytes are mediated through the Gs protein subunit, activating the adenylyl cyclase/cAMP signaling cascade (Kimura et al. 2001). However, both TSH and some TRAb activate a cAMP-independent cascade that increases phosphoinositide 3-kinase (PI3K) activity with the subsequent phosphorylation of AKT (Zaballos et al. 2008, Morshad et al. 2009), a signaling pathway that plays a central role in adipocyte differentiation (Xu \& Liao 2004). We undertook this study to determine whether M22, a highaffinity human monoclonal IgG1 $\lambda$-chain stimulatory antibody directed against a conformational TSHR epitope (Sanders et al. 2003, 2004), or TSH stimulates adipogenesis in orbital preadipocytes from patients with GO. We additionally studied the engagement of the adenylyl cyclase and PI3K signaling cascades in orbital preadipocytes to better understand the signaling mechanisms that might be involved and exploited to develop new therapeutic strategies for patients with GO.

\section{Materials and methods}

\section{Cell cultures}

Orbital adipose tissue specimens were obtained from euthyroid patients during the course of orbital decompression surgery for severe GO. The study was approved by the Mayo Clinic Institutional Review Board and carried out according to IRB guidelines. The orbital adipose/connective tissue specimens were transported to the laboratory, minced, and placed directly in plastic culture dishes, allowing fibroblasts to proliferate as described previously (Bahn et al. 1989). Briefly, cells were propagated in medium 199 containing $20 \%$ fetal bovine serum (FBS; HyClone Laboratories, Inc., Logan, UT, USA), penicillin $(100 \mathrm{U} / \mathrm{ml})$, and gentamycin $(20 \mu \mathrm{g} / \mathrm{ml})$ in a humidified $5 \% \mathrm{CO}_{2}$ incubator at $37^{\circ} \mathrm{C}$, and maintained in $75 \mathrm{~mm}^{2}$ flasks with medium 199 containing 10\% FBS and antibiotics.

Some studies were performed to determine the impact on adipogenesis of M22, a stimulatory TRAb derived from a patient with Graves' hyperthyroidism (M22; Kronus, Boise, ID, USA; \# M22-1b; (Sanders et al. 2003, 2004), bovine TSH (Sigma Aldrich Co.; \# T-8931), or the insulin-like growth factor 1 (IGF1) analog, Des 1,3 (GroPep, Thebarton, Australia). For these studies, confluent orbital fibroblasts were treated for 10 days with bovine TSH $(0 \cdot 1-10 \cdot 0 \mathrm{U} / 1$ and $1 \cdot 7-170 \mathrm{nM})$, M22 $(0 \cdot 1-100 \mathrm{ng} / \mathrm{ml}$ and $0 \cdot 67-670 \mathrm{pM})$, and IGF1 (Des 1,3 analog; $10 \mathrm{ng} / \mathrm{ml}$; used as a positive control for adipogenesis), or were untreated and cultured in adipocyte differentiation medium (without insulin) consisting of serum-free DMEM/Ham's F-12 medium (1:1; Sigma) supplemented with biotin $(33 \mu \mathrm{M})$, pantothenic acid $(17 \mu \mathrm{M})$, transferrin $(10 \mu \mathrm{g} / \mathrm{ml})$, triiodothyronine $\left(\mathrm{T}_{3}\right) \quad(0.2 \mathrm{nM})$, carbaprostacyclin (cPGI $2 ; 0 \cdot 2 \mu \mathrm{M}$; Calbiochem, La Jolla, CA, USA), and, for the first 4 days only, dexamethasone $(1 \mu \mathrm{M})$ and isobutylmethylxanthine (IBMX; $0 \cdot 1 \mathrm{mM}$ ). The media were replaced every 3-4 days during the 10-day differentiation period. Following the 10-day differentiation period, cells were harvested and total RNA was isolated for RT-PCR analysis of adipocyte-related genes.

In other experiments to assess the role of PI3K or cAMP signaling in M22- or TSH-mediated adipogenesis, confluent orbital fibroblasts were cultured for 10 days in insulin-free adipocyte differentiation medium (as mentioned above) containing the same treatments as described earlier. In addition, some of the wells were treated with the PI3K inhibitor LY294002 (10 or $50 \mu \mathrm{M})$ throughout the 10-day differentiation period. To determine whether insulin treatment might enhance adipogenesis in M22-, TSH-, or IGF1-treated cells, insulin $(1 \mu \mathrm{M})$ was added to some of the wells. Following the 10-day differentiation period, cells were harvested and total RNA was isolated for RT-PCR analysis of adipocyte-related genes.

For studies aimed at investigating the role of PI3K or cAMP in M22 or TSH signaling (apart from their impact on adipogenesis), orbital fibroblasts were plated in 96-well dishes and grown to confluence in the culture medium as described earlier. In order to synchronize the signaling event, cells were subsequently serum and nutrient starved for $24 \mathrm{~h}$. Experiments were carried out for between 1 and $30 \mathrm{~min}$ in insulin-free adipocyte differentiation medium. Cells received either no treatment (negative control), bovine TSH $(0 \cdot 1-10 \cdot 0 \mathrm{U} / 1$ and $1 \cdot 7-170 \mathrm{nM})$ or M22 $(0 \cdot 1-100 \mathrm{ng} / \mathrm{ml}$ and $0 \cdot 67-670 \mathrm{pM})$. In addition, some of the wells were treated with LY294002 $(50 \mu \mathrm{M}$; SABiosciences; Fresdrick, MD, USA), a specific inhibitor of PI3K, an enzyme required for AKT phosphorylation or a cAMPdependent protein kinase peptide inhibitor $(10 \mu \mathrm{M}$; PKA \#V5681; Promega), an inhibitor of cAMP production. At the end of the treatment periods, cells or supernatants were collected for the measurement of AKT phosphorylation or cAMP production.

\section{Real-time RT-PCR analyses}

Total RNA was isolated from orbital cultures by the RNeasy kit (Qiagen) according to the manufacturer's protocol. cDNA was synthesized using $750 \mathrm{ng}$ total RNA incubated with random hexamers, followed by reverse transcription reaction in a $100 \mu$ l reaction volume with 6.25 units of Multiscribe Reverse Transcriptase (Applied Biosystems, Foster City, CA, USA). 
The conditions used were $25^{\circ} \mathrm{C}$ for $10 \mathrm{~min}, 37^{\circ} \mathrm{C}$ for $60 \mathrm{~min}$, and $95^{\circ} \mathrm{C}$ for $5 \mathrm{~min}$.

Oligonucleotide primers and TaqMan probes for $T S H R$ and GAPDH, and genes encoding the adipocyte markers adiponectin (an adipocytokine exclusively expressed and secreted by adipose tissue) and leptin (synthesized and secreted primarily by adipocytes) were purchased from Applied Biosystems. Expression of $G A P D H$ was used to correct for differences in the amount of total RNA added to a reaction and to compensate for different levels of inhibition during reverse transcription of RNA and during PCR.

Quantitative PCR was performed in a 96-well optical reaction plate. Amplification reactions contained cDNA equivalent of $5 \mathrm{ng}$ total RNA, $900 \mathrm{nM}$ forward and reverse primers, and $250 \mathrm{nM}$ probes in a volume of $25 \mu \mathrm{l}$ using the Universal TaqMan 2X PCR Master mix (Applied Biosystems). Reaction mixture, without the cDNA, was used as no template control. The thermal cycling conditions used were $2 \mathrm{~min}$ at $50^{\circ} \mathrm{C}$ for optimal AmpErase UNG activity, $10 \mathrm{~min}$ at $95^{\circ} \mathrm{C}$ to activate Amplitaq Gold DNA Polymerase, followed by 40 cycles at $95^{\circ} \mathrm{C}$ for $15 \mathrm{~s}$ and $60^{\circ} \mathrm{C}$ for $1 \mathrm{~min}$. The target genes and $G A P D H$ were amplified in separate wells. All reactions were performed in duplicate in the ABI PRISM 7700 Sequence Detector (Applied Biosystems), and the data were pooled. The standard curve method was used to quantify the expression of the various genes and GAPDH rRNA in each sample. For each experimental sample, a gene was considered not to be expressed if amplification was not detected by cycle 40. The normalized results were expressed as the ratio of RNA (pg) of the target gene to RNA (pg) of GAPDH rRNA. The expression level of each mRNA species in the GO cell cultures was compared with that ins untreated parallel cultures and expressed as fold increase relative to control levels.

\section{Measurement of AKT phosphorylation by ELISA}

AKT protein phosphorylation induced by M22 or TSH treatment of orbital cells was measured using a commercial Cellular Activation of Signaling ELISA (CASE) kit (AKT S473 (FE-001); SABiosciences Corp.). This cell-based ELISA kit quantifies the amount of activated (phosphorylated serine 473) AKT (phosphorylated AKT, pAKT) protein relative to total AKT protein. Results are expressed as fold increase in pAKT protein relative to parallel untreated cultures.

\section{Western blotting}

In order to assess AKT and pAKT protein levels in M22treated cells, confluent orbital fibroblasts were exposed for $60 \mathrm{~min}$ to M22 $(10 \mathrm{ng} / \mathrm{ml})$, LY294002 $(50 \mu \mathrm{M})$, M22 plus LY294002, or no treatment. In other experiments designed to study the role of PI3K signaling in M22-mediated adipogenesis, confluent orbital fibroblasts were cultured for 10 days in insulin-free adipocyte differentiation medium containing M22 (10 ng/ml), LY294002 $(10 \mu \mathrm{M})$, M22 plus LY294002, or no treatment. Cell protein was extracted using the complete lysis-M, EDTA free protocol to extract total cytoplasmic and nuclear protein (Roche \# 04719964 001). Extracts were subjected to electrophoresis on $4-12 \%$ Bis-Tris gel, electrotransferred to polyvinylidene fluoride membrane, and blotted with primary antibody against pAKT, AKT, adiponectin, CCAAT/enhancer-binding protein $\alpha$ $(\mathrm{C} / \mathrm{EBP} \alpha$; Cell Signaling Technology, Danvers, MA, USA; \# 9271S, 9272, 2789, 2295 respectively), or GAPDH at 1:1000 dilution. The appropriate secondary IgG-HRP-linked conjugate (Cell Signaling, \# 7074) at 1:2000 dilution was applied, followed by enhanced chemiluminescence detection.

\section{Measurement of cAMP production}

Levels of cAMP were measured by Cyclic-AMP Assay (R\&D Systems, Minneapolis, MN, USA; \#KGE002B) using a polyclonal antibody that competitively bound cAMP in the standards or sample supernates. Results are expressed as fold increase in cAMP production relative to parallel untreated cultures.

\section{Statistical analyses}

The paired $t$-test was used to evaluate the significance of differences in means for continuous variables, with values presented as the mean \pm s.D. The Mann-Whitney Rank Sum test was used to assess differences between the groups. A $P$ value of $\leq 0.05$ was considered to be statistically significant.

\section{Results}

\section{M22 and TSH enhance adipogenesis in GO orbital cultures}

Treatment of GO orbital cultures $(n=10)$ with M22 $(1 \cdot 0$ or $10 \mathrm{ng} / \mathrm{ml}$ ) during culture for 10 days in insulin-free differentiation medium resulted in increased adiponectin mRNA levels relative to control cultures at $10 \mathrm{ng} / \mathrm{ml}$ $(2 \cdot 6 \pm 0 \cdot 7$-fold; $P=0 \cdot 03)$, with M22 at $1 \cdot 0 \mathrm{ng} / \mathrm{ml}$ not reaching significance $(P=0 \cdot 24$; Fig. $1 \mathrm{~A})$. Treatment with TSH $(1$ or $10 \mathrm{U} / \mathrm{l})$ resulted in increased adiponectin mRNA levels at both doses $(1 \mathrm{U} / 1 \mathrm{TSH}=9 \cdot 5$ $\pm 5 \cdot 0$-fold, $P=0 \cdot 023 ; 10 \mathrm{U} / 1 \mathrm{TSH}=13 \cdot 2 \pm 5 \cdot 8$-fold, $P=0 \cdot 048$; Fig. 1A). Positive control cultures containing IGF1 (Des 1,3 analog; $10 \mathrm{nM}$ ) showed elevated levels of adiponectin mRNA $(152 \cdot 4 \pm 63 \cdot 4$-fold, $P=0 \cdot 025$; Fig. 1A). 

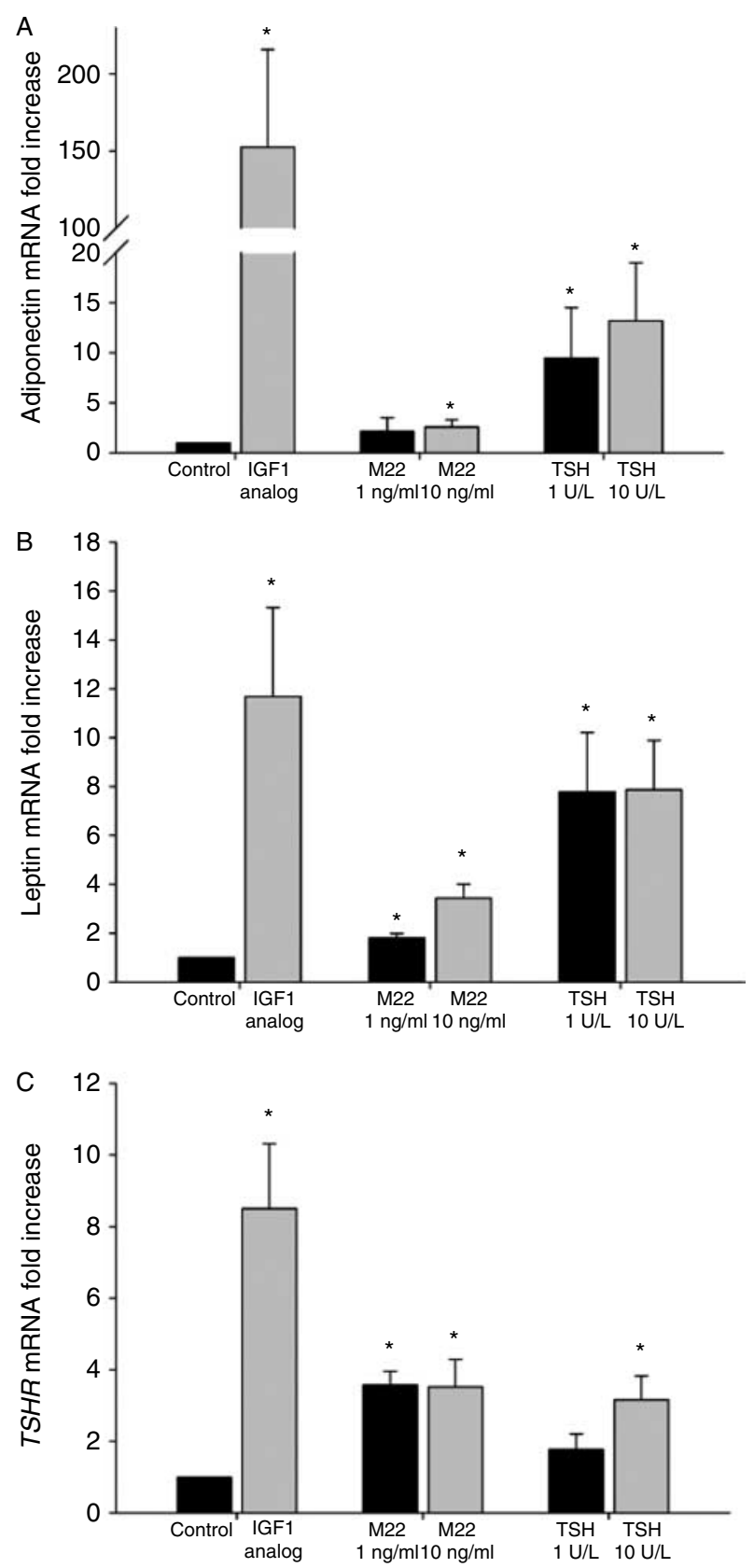

Figure 1 Effect of treatment with M22 ( 1.0 or $10 \mathrm{ng} / \mathrm{ml}$ ), TSH ( 1 or $10 \mathrm{U} / \mathrm{l})$, or the positive control IGF1 Des 1,3 analog $(10 \mathrm{ng} / \mathrm{ml})$ on adipogenesis of $\mathrm{GO}$ orbital preadipocytes $(n=10)$ cultured for 10 days in insulin-free differentiation medium. Results are expressed as mean \pm S.D. fold increase (relative to control untreated cultures) in mRNA levels encoding adipocyte-associated genes; A) adiponectin; B) leptin; and C) TSH receptor. ${ }^{*} P<0.05$.

Levels of leptin mRNA were also increased following treatment with M22 ( $1 \mathrm{ng} / \mathrm{ml}=1 \cdot 8 \pm 0 \cdot 2$-fold, $P=0 \cdot 002 ; 10 \mathrm{ng} / \mathrm{ml}=3 \cdot 4$-fold $\pm 0 \cdot 6, P=0 \cdot 001)$, TSH $(1 \mathrm{U} / 1=7 \cdot 8 \pm 2 \cdot 4$-fold, $P=0 \cdot 019 ; 10 \mathrm{U} / 1=7 \cdot 9 \pm 2 \cdot 0$ fold, $P=0 \cdot 007)$, or the IGF1 analog $(11 \cdot 7 \pm 3 \cdot 6$-fold,
$P=0 \cdot 015$; Fig. 1B). Similarly, TSHR mRNA levels were elevated in cultures treated with M22 $(1 \mathrm{ng} / \mathrm{ml}=$ $3 \cdot 6 \pm 0 \cdot 4$-fold, $P<0 \cdot 001 ; 10 \mathrm{ng} / \mathrm{ml}=3 \cdot 5 \pm 0 \cdot 8$-fold, $P=0 \cdot 007)$, TSH $(1 \mathrm{U} / 1=1 \cdot 8 \pm 0 \cdot 4$-fold, $P=0 \cdot 078$; $10 \mathrm{U} / 1=3 \cdot 2 \pm 0 \cdot 7$-fold, $P=0 \cdot 008)$, and IGF1 analog $(8 \cdot 5 \pm 1 \cdot 8$-fold, $P=0 \cdot 001$; Fig. 1C). Finally, while we found that the addition of insulin $(1 \mu \mathrm{M})$ to $\mathrm{M} 22-$ or TSH-treated cultures and control cultures enhanced the overall magnitude of adipogenesis in all cultures, the fold increase in adipogenesis was not different from that found in insulin-free cultures (data not shown).

Visual inspection of cells cultured for 10 days in insulin-free adipocyte differentiation medium and stained with oil red-O revealed clearly increased staining in IGF1 (Des 1,3 analog)-treated orbital cultures (Fig. 2A) compared with control cultures (Fig. 2B). In cultures treated with either M22 $(10 \mathrm{ng} / \mathrm{ml})$ or TSH (10 U/1), small foci of increased oil red-O staining were apparent on visual inspection (Fig. 2C and D respectively).

\section{M22 and TSH stimulate dose- and time-dependent increases in AKT protein phosphorylation}

GO orbital fibroblast cultures $(n=8)$ treated with M22 $(0 \cdot 1-100 \mathrm{ng} / \mathrm{ml})$ or TSH $(0 \cdot 001-10 \mathrm{U} / 1)$ for $5 \mathrm{~min}$ showed a dose-dependent increase in pAKT (assessed using an ELISA) that was significant compared with parallel control cultures beginning at $0 \cdot 1 \mathrm{ng} / \mathrm{ml}$ for M22 and at $0 \cdot 1 \mathrm{U} / 1$ for TSH (Fig. 3). In addition, treatment of orbital cultures $(n=8)$ for 1,5 , 10 , or $30 \mathrm{~min}$ with either M22 $(5 \mathrm{ng} / \mathrm{ml})$ or $\mathrm{TSH}$ $(10 \mathrm{U} / 1)$ showed a time-dependent increase in pAKT protein that was significant at each time point for each treatment compared with parallel control cultures (Fig. 4).

\section{M22-stimulated increase in AKT protein phosphory- lation is inhibited by a specific PI3K inhibitor}

Treatment of GO orbital fibroblast cultures $(n=8)$ for $1,5,10$, or $30 \mathrm{~min}$ with M22 $(5 \mathrm{ng} / \mathrm{ml})$ in combination with the specific PI3K inhibitor LY294002 $(50 \mu \mathrm{M})$ showed decreased pAKT protein levels at each time point relative to cultures treated with M22 alone, reaching significance at $30 \mathrm{~min}$ (Fig. 4). While there was a trend toward decreased pAKT protein levels in TSH-treated cultures exposed to LY294002 compared with those treated with TSH alone, this did not reach significance. Western blotting of protein extracts from GO orbital fibroblast cultures $(n=2)$ treated for $60 \mathrm{~min}$ with M22 (5 ng/ml), M22 plus LY294002, or LY294002 alone showed increased AKT phosphorylation in cultures treated with M22 alone and inhibition of this effect in cells treated with both M22 and LY294002 (Fig. 5). 

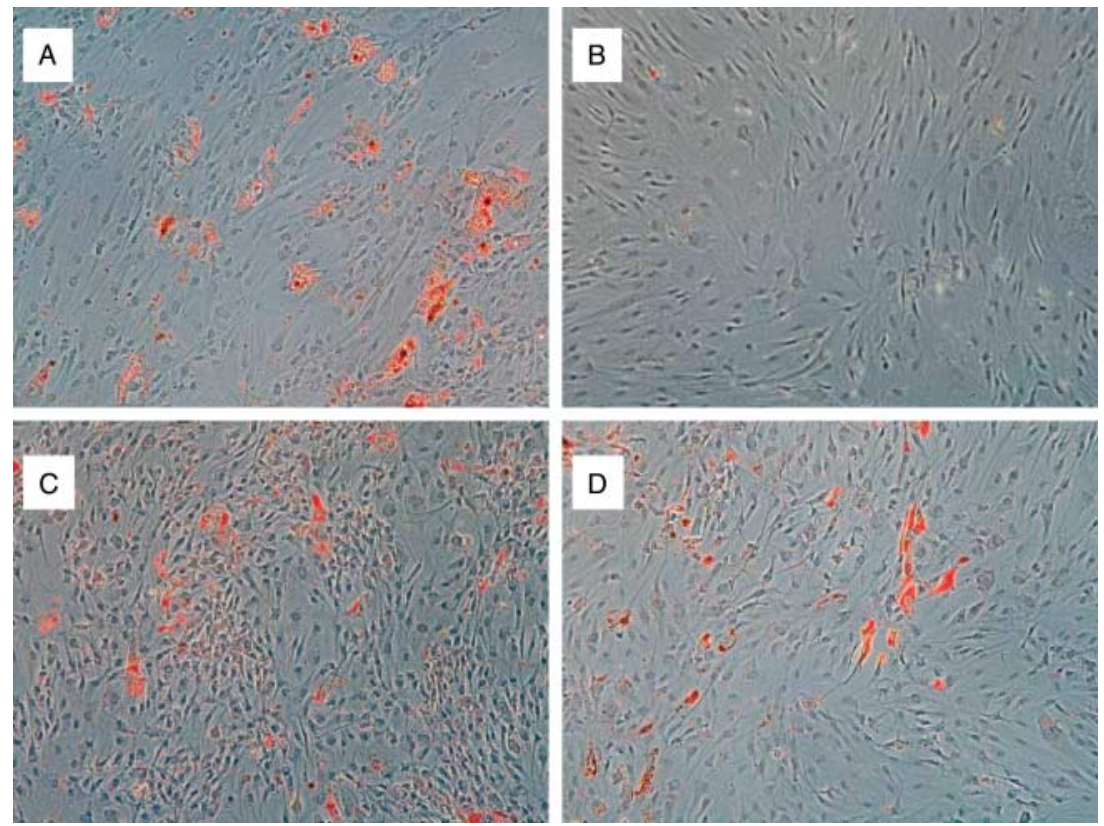

Figure 2 Oil red-O staining of orbital adipocytes that were cultured for 10 days in insulinfree adipocyte differentiation medium containing A) IGF1 (Des 1,3 analog; $10 \mathrm{ng} / \mathrm{ml}$ ); B) untreated; C) M22 (10 ng/ml); or D) TSH (10 U/l).

To demonstrate specificity of the LY294002 effect, Fig. 5 shows increased AKT phosphorylation in cells treated for $60 \mathrm{~min}$ with IGF1 (Des 1,3 analog; $10 \mathrm{ng} / \mathrm{ml}$ ) and inhibition of this effect in cells treated with both IGF1 and LY294002.

\section{M22-enhanced adipogenesis is inhibited by a specific PI3K inhibitor}

We found a decrease in adiponectin mRNA levels in orbital cultures $(n=4)$ treated during the entire 10-day differentiation period with both M22 $(10 \mathrm{ng} / \mathrm{ml})$ and LY294002 $(50 \mu \mathrm{M})$ compared with cultures treated with M22 alone $(67 \pm 12 \cdot 2 \%, P=0 \cdot 021$; Fig. 6$)$. At the same time, levels of the housekeeping gene $G A P D H$ did not change during the 10-day incubation period in either set of cultures, remaining at $\sim 19$ cycles throughout. In other experiments, cultures treated with both M22 and LY294002 showed levels of adiponectin mRNA that were approximately tenfold than those found in cultures treated with LY294002 alone (data not shown). While cultures treated with both TSH (10 U/l) and LY294002 showed a trend toward diminished adiponectin mRNA levels compared with TSH-treated cultures, this did not reach significance $(42 \cdot 7 \pm 6 \cdot 0 \%)$.

We also found a decrease in protein levels for adiponectin (an adipocyte-specific protein) and $\mathrm{C} / \mathrm{EBP} \alpha$ (an adipocyte-related protein) in cultures treated during the entire 10-day differentiation period with both M22 (10 ng/ml) and LY294002 (at the lower dose of $10 \mu \mathrm{M})$ compared with cultures treated with M22 alone (Fig. 7). These studies also demonstrated an increase in both adiponectin and $\mathrm{C} / \mathrm{EBP} \alpha$ protein levels in M22-treated cultures compared with untreated cultures, confirming the stimulation of adipogenesis by M22 on the protein level (Fig. 7).

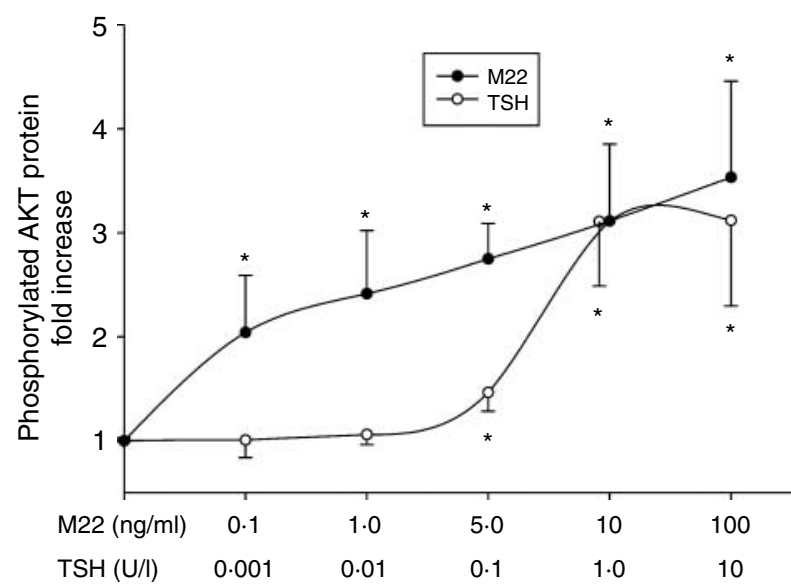

Figure 3 Effect of M22 $(0 \cdot 1-100 \mathrm{ng} / \mathrm{ml})$ or TSH $(0.001-10 \mathrm{U} / \mathrm{l})$ treatment for $5 \mathrm{~min}$ on phosphorylated AKT (pAKT) protein levels in GO orbital fibroblast cultures $(n=8)$. ELISA results are expressed as mean \pm S.E.M. fold increase in pAKT levels relative to parallel untreated cultures. ${ }^{*} P<0.05$. 


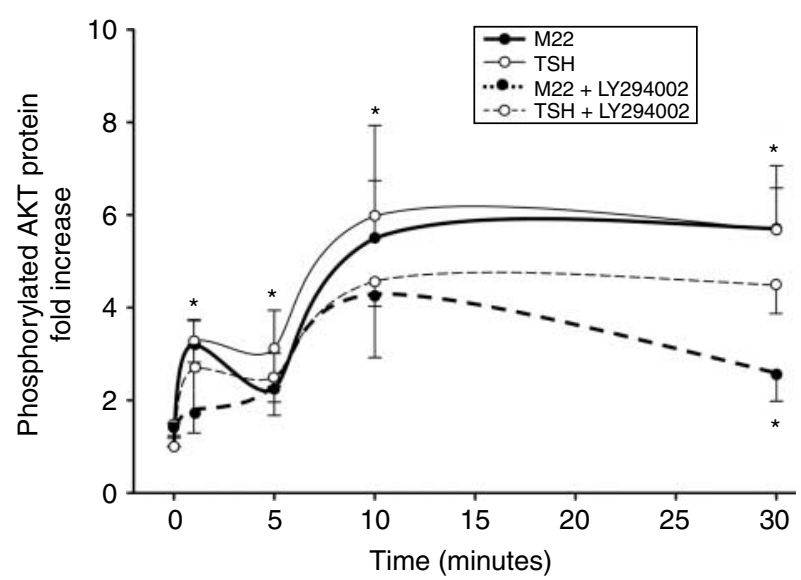

Figure 4 Effect of $1,5,10$, or 30 min treatment with M22 $(5 \mathrm{ng} / \mathrm{ml}$; filled circles), TSH (10 U/l; open circles), or agent in combination with the specific PI3K inhibitor LY294002 $(50 \mu \mathrm{M})$ on phosphorylated AKT ( $p A K T$ ) protein levels in GO orbital fibroblast cultures $(n=8)$. ELISA results are expressed as mean \pm S.E.M. fold increase in PAKT levels (solid lines) relative to parallel untreated cultures or to fold decrease in pAKT levels (broken lines) relative to parallel cultures treated with M22 or TSH alone. ${ }^{*} P<0.05$.

\section{Both M22 and TSH stimulate cAMP production}

GO orbital fibroblast cultures $(n=8)$ treated for between 1 and $30 \mathrm{~min}$ with M22 $(0 \cdot 1-100 \mathrm{ng} / \mathrm{ml}$; equivalent to $0 \cdot 001-1 \mu \mathrm{g} / \mathrm{ml})$ or bovine TSH $(0 \cdot 01-10 \mathrm{U} / \mathrm{l})$ showed a dose-dependent increase in cAMP production that was significant for M22 at $10 \mathrm{ng} / \mathrm{ml}$ and for TSH at $1 \mathrm{U} / 1$ (data not shown). In addition, treatment of cultures for $1,5,10$, or $30 \mathrm{~min}$ with M22 $(100 \mathrm{ng} / \mathrm{ml})$ or TSH $(10 \mathrm{U} / \mathrm{l})$ showed a time-dependent increase in cAMP production (data not shown). While there was a trend toward decreased adiponectin mRNA levels in cultures treated for 10 days with either M22 or TSH and the cAMP-dependent protein kinase peptide inhibitor PKA \#V5681 (44 18 and $24 \pm 7 \%$ respectively), this did not reach significance (data not shown).

\section{Discussion}

M22 is a potent stimulatory human monoclonal autoantibody to TSHR that also possesses powerful TSH-binding inhibiting activity (Sanders et al. 2003, 2004). Our finding that this antibody is capable of enhancing adipocyte differentiation in cultured human orbital fibroblast cultures (containing $\sim 15-20 \%$ preadipocytes, defined as cells capable of differentiating into mature adipocytes) is, to our knowledge, the first demonstration of an autoantibody being pro-adipogenic in any cell system. That TSH is a pro-adipogenic factor in the conversion of mouse embryonic stem cells into adipocytes has been reported by Lu \& Lin (2008). These investigators found that treatment with TSH
$(1 \mathrm{U} / \mathrm{l})$ increased adipogenesis in the absence of the adipogenic factors insulin, $\mathrm{T}_{3}$, and the peroxisome proliferator-activated receptor- $\gamma$ (PPAR $\gamma)$ agonist rosiglitazone. They found elevated levels of mRNA encoding early to intermediate adipocyte marker genes, including $C / E B P \beta$ and PPAR but did not measure genes associated with terminal adipocyte differentiation. However, they demonstrated a timedependent increase in lipid accumulation (oil red-O staining of lipid droplets) in these cells, suggesting that terminal differentiation was complete. They also found an increase in TSHR mRNA and immunofluorescent protein expression in embryonic cells containing lipid droplets, as well as an increase in TSH-stimulated cAMP production, as was reported in earlier studies showing enhanced TSHR expression in differentiated orbital adipocytes (Valyasevi et al. 1999, Crisp et al. 2000). Our studies were performed in culture medium that also did not contain insulin. However, in contrast to the studies by $\mathrm{Lu} \& \mathrm{Lin}$, our cultures did contain $\mathrm{T}_{3}$ and IBMX because we have been unable to detect adipogenesis in M22- or TSH-treated cultures in the absence of these adipogenic factors. This suggests that while M22 and TSH are pro-adipogenic factors in our system, they require the presence of cAMP and other factors to activate the process.

In a study by Zhang et al. (2006), activation of TSHR by introduction of an activating mutant receptor into human orbital preadipocytes using retroviral vectors resulted in an increase in early adipocyte differentiation, as demonstrated by two- to eightfold elevations in levels of the early to intermediate markers, $C / E B P \beta$ and $P P A R \gamma$. In these studies, levels of mRNA encoding lipoprotein lipase (LPL; a late adipocyte marker) were at the limit of detection. Expression of the activating TSHR also produced a two- to sixfold increase in basal cAMP levels and 4- to 16-fold cAMP elevation in TSHtreated cells. While no obvious oil red-O staining was apparent on visualization in mutant or WT TSHRexpressing orbital cells, quantitation revealed measurable staining with somewhat higher levels in the mutant

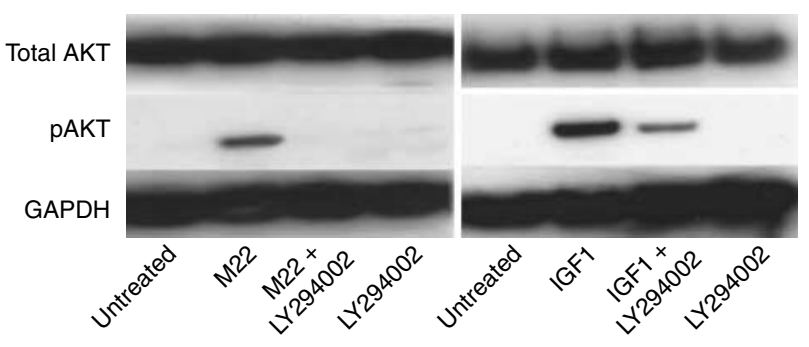

Figure 5 Western blots showing total and phosphorylated AKT (pAKT) and GAPDH protein bands in confluent GO orbital fibroblast cultures exposed to the indicated treatments for $60 \mathrm{~min}$. Left: 1) no treatment; 2) M22 (10 ng/ml); 3) M22 plus LY294002 (50 $\mu \mathrm{M})$; or 4) LY294002 alone. Right: 1) no treatment; 2) IGF1 (Des 1,3 analog $10 \mathrm{ng} / \mathrm{ml}$; 3) IGF1 plus LY294002; or 4) LY294002 alone. 


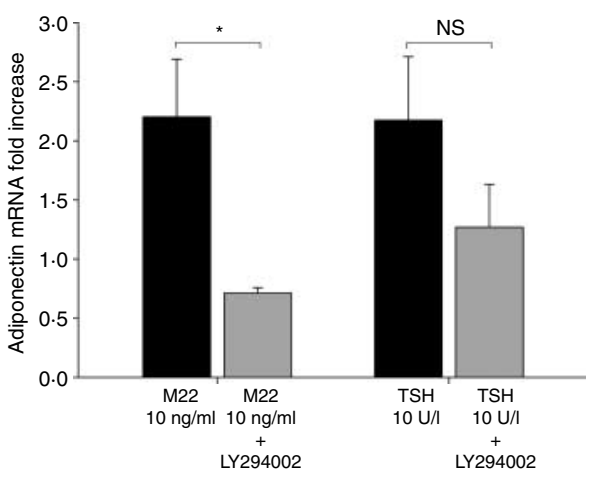

Figure 6 Effect of M22 (10 ng/ml) or TSH $(10 \mathrm{U} / \mathrm{l})$ and the specific PI3K inhibitor LY294002 on adiponectin mRNA levels in GO orbital preadipocytes $(n=8)$ cultured for 10 days in insulin-free differentiation medium. Results are expressed as mean \pm S.D. fold increase in adiponectin mRNA levels relative to control untreated cultures. ${ }^{\star} P<0.05$.

TSHR than in the WT-TSHR-transfected cells. However, while the basal lipid content of activated cells was higher, it failed to increase in response to a PPAR $\gamma$ agonist, suggesting that TSHR activation renders these transfected cells refractory to PPAR $\gamma$-induced adipogenesis. Furthermore, while the mutant TSHRcontaining cultures subjected to adipocyte differentiation medium for 10 days showed somewhat elevated levels of early and intermediate stages of adipocyte differentiation compared with the WT-TSHR-transfected cells, they failed to show elevated levels of LPL.

In our studies, in contrast to those of Zhang et al. (2006), we found clusters of lipid-containing vacuoles, evidence of late-adipocyte gene expression (increased levels of adiponectin, leptin, and TSHR mRNA) in our cultures treated with either M22 or TSH, suggesting the presence of mature adipocytes. Differences found in the extent of adipogenesis between our TSH- or M22-stimulated cells and the TSHR-transfected orbital preadipocytes used in the Zhang study may be explained by changes in the adipogenic potential of the latter cells owing to the transfection itself, rendering them refractory to PPAR $\gamma$ activation and thus unable to differentiate into mature fat cells. In a subsequent study using the same system, Zhang et al. (2009a) reported that Gs $\alpha$ (cAMP) signaling inhibits and that $\mathrm{G} \beta \gamma(\mathrm{PI} 3 \mathrm{~K})$ signaling enhances the later stages of adipogenesis. As our TSH- or M22-treated cultures expressed higher levels of TSHR than untreated cultures, and undifferentiated GO orbital fibroblasts express only very low levels of TSHR (Heufelder et al. 1993), it is possible that TSH and M22 act to upregulate TSHR expression, and that this in turn further increases PI3K activity and results in enhanced adipogenesis. In another study, Zhang et al. (2009b) found increased production of hyaluronan by their mutant TSHR-transfected GO orbital preadipocytes, as well as by GO orbital preadipocytes treated with two other TRAb (one stimulatory and the other neutral), suggesting that TSHR activation with PI3K signaling may contribute to the orbital accumulation of hyaluronan observed in GO.

In a recent study characterizing TRAb-induced signaling cascades, Morshad et al. (2009) have assessed the interaction of M22 with the TSHR in the Fisher Rat Thyroid cell Line (FRTL-5). They demonstrated 1.5- to $2 \cdot 5$-fold stimulation of cAMP as well as dose- and timedependent increases in pAKT in FRTL-5 cells treated with either M22 or bovine TSH. While our findings are similar and the bovine TSH doses we used were comparable, our doses of M22 were 10- to 100-fold lower. Therefore, it appears that GO orbital preadipocytes and FRTL-5 cells are similarly sensitive to TSH or M22 in terms of enhanced cAMP production and to TSH in its augmentation of pAKT levels. However, our results suggest that orbital preadipocytes may be more sensitive to the effect of M22 on pAKT levels than are FRTL-5 cells.

The differentiation of precursor cells (preadipocytes) into mature adipocytes is controlled by a complex network of signaling pathways, closely regulated by transcription factors, including members of the C/EBP and PPAR families (Rosen \& MacDougald 2006). The initiation of adipocyte differentiation appears to require cAMP, which generally functions through the classical protein kinase A pathway to phosphorylate and activate key regulatory transcription factors (Engelman et al. 1999). Terminal adipocyte differentiation is promoted by the activity of several kinases, particularly kinases of the PI3K/AKT pathway and those activating p38 mitogen-activated protein kinases (Kohn et al. 1996), and results in the synthesis of adipocyte-secreted products, including adiponectin (the most abundant transcript in human adipose tissue) and leptin (Gregiore et al. 1998).

We found that treatment of GO orbital preadipocytes with the specific PI3K inhibitor LY294002 in combination with M22 decreases the levels of adiponectin mRNA as well as of adiponectin and $\mathrm{C} / \mathrm{EBP} \alpha$ protein

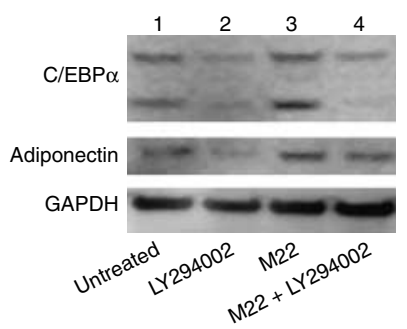

Figure 7 Western blots showing C/EBP $\alpha$ (top), adiponectin (middle), and GAPDH (bottom) protein bands in confluent GO orbital fibroblast cultures exposed throughout 10 days in culture to the indicated treatments. Lane 1) no treatment; 2) LY294002 $(10 \mu \mathrm{M})$; 3) M22 (10 ng/ml); 4) M22 plus LY294002. 
compared with cultures treated with M22 alone. While there was a similar trend observed in TSH-treated cultures, this did not reach significance. These findings suggest that the observed stimulatory effect of M22 on adipogenesis in these cells may involve the PI3K pathway. However, because inhibition of adipogenesis by LY294002 was not complete and cultures treated with the cAMP-dependent protein kinase peptide inhibitor also showed some degree of inhibition (albeit not significant in magnitude), it is likely that the cAMP pathway also plays a role in adipogenesis in these cells.

AKT is an important mediator of insulin-activated IGF1 receptor (IGF1R) signaling that plays a central role in the regulation of adipocyte differentiation (Xu $\&$ Liao 2004). As expected, we found the IGF1 analog Des 1,3 to be a potent stimulator of adipogenesis in GO orbital preadipocytes. Recent studies have suggested that autoantibodies directed against the IGF1R may circulate in patients with GO, recognize the receptor on orbital preadipocytes, and initiate some of the tissue changes characteristic of the disease (Smith \& Hoa 2004). In addition, evidence suggests that physical and functional relationships may exist between IGF1R and TSHR in orbital fibroblasts (Smith 2003). It is therefore possible that these relationships may facilitate the engagement of the PI3K/AKT pathway by autoantibodies in GO directed against either or both of these receptors. Our results suggest, however, that stimulatory TRAb are themselves capable of enhancing orbital adipogenesis in $\mathrm{GO}$ without implicating the presence of autoantibodies-directed against IGF1R.

The relevance of our findings to Graves' hyperthyroidism and GO stems from the fact that the TRAb used in these studies was a human monoclonal stimulatory TRAb (Sanders et al. 2004b), while the cells were derived from the orbits of patients with GO. The overproduction of thyroid hormones by thyroid follicular epithelial cells in Graves' disease is caused by circulating stimulatory autoantibodies targeting TSHR (Rapoport et al. 1998). Although enhanced adipogenesis within the GO orbit contributes to expansion of the orbital adipose tissues and results in many of the clinical manifestations of the disease (Bahn 2010), the cause of this tissue remodeling is not understood. Our finding that a TRAb stimulates human orbital preadipocytes to differentiate into mature adipocytes suggests that TSHR-directed autoantibodies in Graves' disease may represent a link between Graves' hyperthyroidism and its ocular manifestations.

The M22 antibody used in our studies is considered 'stimulatory', because it is similar to TSH in that it stimulates thyrocytes via Gas-cAMP/protein kinase A/ERK-coupled signaling network. This antibody is also capable of engaging $\mathrm{G} \alpha \mathrm{q}$ subunits in thyrocytes that activate phospholipase C (Morshad et al. 2009). Other TSHR-directed antibodies reduce TSH action at the TSHR (so called 'blocking antibodies') or have no influence on TSH binding (neutral antibodies). Some of these antibodies have recently been shown to use signaling cascades not activated by TSH (Morshad et al. 2009). We found M22 to be capable of engaging both $\mathrm{G}$ protein subunits in orbital fibroblasts, as evidenced by its stimulation of both cAMP production and levels of pAKT. It may be that the variable clinical manifestations of GO, and the occurrence of 'euthyroid' GO, are attributable to the activation of various signaling networks and downstream effectors in orbital fibroblasts by the stimulatory, inhibitory, and neutral TSHR antibodies known to be circulating in patients with Graves' disease.

In conclusion, we present the novel finding that M22 is a pro-adipogenic factor in GO orbital preadipocytes, and that this occurs through PI3K pathway activation at very low concentrations of the antibody. These findings suggest a mechanism whereby particular TRAb in Graves' disease may play a role in the development of the ocular manifestations of the disease. In addition, they point toward the PI3K signaling pathway as a potential target for novel GO therapies. Better understanding of the various signaling cascades activated by individual TRAb in GO orbital fibroblasts will improve our understanding of the development and the heterogeneous nature of the extrathyroidal manifestations of Graves' disease, and may aid in the development of novel therapies for GO.

\section{Declaration of interest}

The authors declare that there is no conflict of interest that could be perceived as prejudicing the impartiality of the research reported.

\section{Funding}

This work was supported by the National Institute of Diabetes, Digestive and Kidney Diseases (grant number DK77814).

\section{References}

Bahn RS 2010 Mechanisms of disease: Graves' ophthalmopathy. New England Journal of Medicine 362 726-738. (doi:10.1056/ NEJMra0905750)

Bahn RS, Gorman CA, Johnson CM \& Smith TJ 1989 Presence of antibodies in the sera of patients with Graves' disease recognizing a 23 kilodalton fibroblast protein. Journal of Clinical Endocrinology and Metabolism 69 622-628. (doi:10.1210/jcem-69-3-622)

Bahn RS, Dutton CM, Natt N, Joba W, Spitzweg C \& Heufelder AE 1998 Thyrotropin receptor expression in Graves' orbital adipose/connective tissues: potential autoantigen in Graves' ophthalmopathy. Journal of Clinical Endocrinology and Metabolism 83 998-1002. (doi:10.1210/jc.83.3.998)

Crisp M, Starkey K, Lane C, Ham J \& Ludgate M 2000 Adipogenesis in thyroid eye disease. Investigative Ophthalmology and Visual Science $\mathbf{4 1}$ 3249-3255. 
Eckstein AK, Plicht M, Lax H, Neuhauser M, Mann K, Lederbogen S, Heckmann C, Esser J \& Morgenthaler NG 2006 Thyrotropin receptor autoantibodies are independent risk factors for Graves' ophthalmopathy and help to predict severity and outcome of the disease. Journal of Clinical Endocrinology and Metabolism 91 3464-3470. (doi:10.1210/jc.2005-2813)

Engelman JA, Berg AH, Lewis RY, Lin A, Lisanti MP \& Scherer PE 1999 Constitutively active mitogen-activated protein kinase kinase 6 (MKK6) or salicylate induces spontaneous 3T3-L1 adipogenesis. Journal of Biological Chemistry 274 35630-35638. (doi:10.1074/jbc. 274.50.35630)

Feliciello A, Porcellini A, Ciullo I, Bonavolonta G, Avvedimento EV \& Fenzi G 1993 Expression of thyrotropin-receptor mRNA in healthy and Graves' disease retro-orbital tissue. Lancet 342 337-338. (doi:10.1016/0140-6736(93)91475-2)

Forbes G, Gorman CA, Brennan MD, Gehring DG, Ilstrup DM \& Earnest Ft 1986 Ophthalmopathy of Graves' disease: computerized volume measurements of the orbital fat and muscle. AJNR. American Journal of Neuroradiology 7 651-656.

Gerding MN, van der Meer JW, Broenink M, Bakker O, Wiersinga WM \& Prummel MF 2000 Association of thyrotrophin receptor antibodies with the clinical features of Graves' ophthalmopathy. Clinical Endocrinology 52 267-271. (doi:10.1046/j.1365-2265.2000.00959.x)

Gregiore F, Smas C \& Sul H 1998 Understanding adipocyte differentiation. Physiological Reviews 78 783-809.

Heufelder AE, Dutton CM, Sarkar G, Donovan KA \& Bahn RS 1993 Detection of TSH receptor RNA in cultured fibroblasts from patients with Graves' ophthalmopathy and pretibial dermopathy. Thyroid 3 297-300. (doi:10.1089/thy.1993.3.297)

Kimura T, Van K, Golstein J, Fusco A, Dumont J \& Roger P 2001 Regulation of thyroid cell proliferation by TSH and other factors: a critical evaluation of in vitro models. Endocrine Reviews 22 631-656. (doi:10.1210/er.22.5.631)

Kohn A, Summers S, Birnbaum M \& Roth R 1996 Expression of a constitutively active Akt Ser/Thr kinase in 3T3-L1 adipocytes stimulates glucose uptake and glucose transporter 4 translocation. Journal of Biological Chemistry 271 31372-31378. (doi:10.1074/jbc. 271.49.31372)

Kumar S, Coenen MJ, Scherer PE \& Bahn RS 2004 Evidence for enhanced adipogenesis in the orbits of patients with Graves' ophthalmopathy. Journal of Clinical Endocrinology and Metabolism 89 930-935. (doi:10.1210/jc.2003-031427)

Lu M \& Lin RY 2008 TSH stimulates adipogenesis in mouse embryonic stem cells. Journal of Endocrinology 196 159-169. (doi:10.1677/JOE07-0452)

Mengistu M, Lukes YG, Nagy EV, Burch HB, Carr FE, Lahiri S \& Burman KD 1994 TSH receptor gene expression in retroocular fibroblasts. Journal of Endocrinological Investigation 17 437-441.

Morshad SA, Latif R \& Davies TF 2009 Characterization of thyrotropin receptor antibody-induced signaling cascades. Endocrinology 150 519-529. (doi:10.1210/en.2008-0878)

Rapoport B, Chazenbalk GD, Jaume JC \& McLachlan SM 1998 The thyrotropin (TSH) receptor: interaction with TSH and autoantibodies. Endocrine Reviews 19 673-716. (doi:10.1210/er.19.6.673)

Rosen ED \& MacDougald OA 2006 Adipocyte differentiation from the inside out. Nature Reviews. Molecular Cell Biology 7 885-896. (doi:10.1038/nrm2066)
Sanders J, Evans M, Premawaradhana L, Depraetere H, Jeffreys J, Richards T, Furmaniak J \& Smith B 2003 Human monoclonal thyroid stimulating autoantibody. Lancet 362 126-128. (doi:10. 1016/S0140-6736(03)13866-4)

Sanders J, Jeffreys J, Depraetere H, Evans M, Richards T, Kiddie A, Brereton K, Premawardhana LD, Chirgadze DY, Nunez Miguel R et al. 2004 Characteristics of a human monoclonal autoantibody to the thyrotropin receptor: sequence structure and function. Thyroid 14 560-570. (doi:10.1089/1050725041692918)

Smith TJ 2003 The putative role of fibroblasts in the pathogenesis of Graves' disease: evidence for the involvement of the insulin-like growth factor-1 receptor in fibroblast activation. Autoimmunity 36 409-415. (doi:10.1080/08916930310001603000)

Smith TJ \& Hoa N 2004 Immunoglobulins from patients with Graves' disease induce hyaluronan synthesis in their orbital fibroblasts through the self-antigen, insulin-like growth factor-I receptor. Journal of Clinical Endocrinology and Metabolism 89 5076-5080. (doi:10.1210/jc.2004-0716)

Smith TJ, Bahn RS \& Gorman CA 1989 Connective tissue, glycosaminoglycans, and diseases of the thyroid. Endocrine Reviews 10 366-391. (doi:10.1210/edrv-10-3-366)

Valyasevi RW, Erickson DZ, Harteneck DA, Dutton CM, Heufelder AE, Jyonouchi SC \& Bahn RS 1999 Differentiation of human orbital preadipocyte fibroblasts induces expression of functional thyrotropin receptor. Journal of Clinical Endocrinology and Metabolism 84 2557-2562. (doi:10.1210/jc.84.7.2557)

Wakelkamp IM, Bakker O, Baldeschi L, Wiersinga WM \& Prummel MF 2003 TSH-R expression and cytokine profile in orbital tissue of active vs. inactive Graves' ophthalmopathy patients. Clinical Endocrinology 58 280-287. (doi:10.1046/j.1365-2265.2003.01708.x)

Xu J \& Liao K 2004 Protein kinase B/AKT 1 plays a pivotal role in insulin-like growth factor-1 receptor signaling induced 3T3-L1 adipocyte differentiation. Journal of Biological Chemistry 279 35914-35922. (doi:10.1074/jbc.M402297200)

Zaballos M, Garcia B \& Santisteban P 2008 G beta gamma dimers released in response to thyrotropin activate phosphoinositide 3-kinase and regulate gene expression in thyroid cells. Molecular Endocrinology 22 1183-1199. (doi:10.1210/me.2007-0093)

Zhang L, Baker G, Janus D, Paddon CA, Fuhrer D \& Ludgate M 2006 Biological effects of thyrotropin receptor activation on human orbital preadipocytes. Investigative Ophthalmology and Visual Science 47 5197-5203. (doi:10.1167/iovs.06-0596)

Zhang L, Paddon C, Lewis MD, Grennan-Jones F \& Ludgate M $2009 a$ Gsalpha signalling suppresses PPARgamma2 generation and inhibits 3T3L1 adipogenesis. Journal of Endocrinology 202 207-215. (doi:10.1677/JOE-09-0099)

Zhang LS, Greyner HJ, Mummert ME \& Petroll WM $2009 b$ Development of a hyaluronan bioconjugate for the topical treatment of melanoma. Journal of Dermatological Science 55 56-59. (doi:10.1016/j.jdermsci.2009.02.014)

Received in final form 10 January 2011

Accepted 14 February 2011

Made available online as an Accepted Preprint 14 February 2011 